\title{
ARTICLE
}

Carbohydrates, glycemic index and diabetes mellitus

\section{Glycaemic and insulinaemic impact of oats soaked overnight in milk vs. cream of rice with and without sugar, nuts, and seeds: a randomized, controlled trial}

\author{
Thomas M. S. Wolever ${ }^{1} \cdot$ Peter J. H. Jones ${ }^{2} \cdot$ Alexandra L. Jenkins $^{1} \cdot$ Rebecca C. Mollard $^{2} \cdot$ Haizhou Wang $^{2}$. \\ Alie Johnston ${ }^{2} \cdot$ Jodee Johnson ${ }^{3} \cdot$ YiFang $\mathrm{Chu}^{3}$
}

Received: 3 August 2018 / Accepted: 7 September 2018 / Published online: 8 October 2018

(c) The Author(s) 2018. This article is published with open access

\begin{abstract}
Background/Objectives Soaking oats overnight in milk renders them ready to eat the next morning, however, it is unknown whether oats prepared this way will retain its relatively low glycaemic and insulinaemic impact. Therefore, we compared the glycaemic, insulinaemic and subjective hunger responses elicited by oats soaked overnight in $110 \mathrm{~g}$ skim-milk (ONO) vs. cooked cream of rice cereal (CR), both with and without inclusions.

Subjects/Methods The project was performed at two research centers (Toronto, Winnipeg) as two separate studies each using a randomized, cross-over design with similar methods. The glycaemic and insulinaemic responses of overnight-fasted participants without diabetes (males:females: Toronto, 24:16; Winnipeg, 20:20) were measured for $3 \mathrm{~h}$ after consuming CR and ONO fed alone (Toronto) or with added sugar, nuts, and seeds (CRsns and ONOsns) (Winnipeg). Participants rated subjective hunger using visual analog scales. Data were analyzed by paired $t$-test. The primary endpoint was $0-2 \mathrm{~h}$ incremental area under the curve (iAUC) for glucose.

Results Mean glucose iAUC was 33\% less, after ONO than CR (mean difference was 39 (51-27) $\mathrm{mmol} \times \mathrm{min} / \mathrm{l}, p<0.0001$ ) and 24\% less, after ONOsns than CRsns (mean difference was 43 (65-21) $\mathrm{mmol} \times \mathrm{min} / \mathrm{l}, p=0.0003$ ). Serum-insulin iAUC was 33\% less, after ONO than CR (mean difference $57(81-40)$ pmol $\times \mathrm{hl}, p<0.0001)$ and $32 \%$ less, after ONOsns than CRsns (966 (1360-572) pmol $\times \mathrm{h} / \mathrm{l}, p<0.0001)$. In both Toronto and Winnipeg, subjective hunger ratings were similar across the two treatments.

Conclusions Oats prepared by soaking overnight in skimmed milk without and with inclusions retain their relatively low glycaemic and insulinaemic impact.
\end{abstract}

\section{Introduction}

Oats elicit a lower glycaemic response than most other breakfast cereals when comparing equivalent amounts of

Electronic supplementary material The online version of this article (https://doi.org/10.1038/s41430-018-0329-1) contains supplementary material, which is available to authorized users.

Thomas M. S. Wolever

twolever@gilabs.com

Glycemic Index Laboratories, Inc., Toronto, ON, Canada

2 Richardson Centre for Functional Foods and Nutraceuticals, University of Manitoba, Winnipeg, MB, Canada

3 Quaker Oats Center of Excellence, PepsiCo R\&D Nutrition, Barrington, IL 60010, USA available carbohydrate (avCHO) [1-4]. Oats are rich in $\beta$-glucan, a highly viscous soluble dietary fiber [5] which, when added to test-meals, reduces postprandial blood-glucose, and insulin responses [6, 7] by increasing the viscosity of the contents of the upper gut $[6,7]$ and thereby delaying the absorption of carbohydrates [8]. Traditionally, oats are cooked in water prior to consumption, a process that not only gelatinizes starch causing more rapid digestion and an increased glycaemic response [9], but also solubilizes $\beta$-glucan which increases its ability to reduce the glycaemic response [10]. Another way to prepare oats is to soak them overnight in milk and consume them cold, the next morning (overnight oats). This reduces morning preparation time, and, thus, may encourage increased consumption of oats. However, it is unknown whether oats soaked overnight in skim-milk (ONO) will retain their relatively low glycaemic and insulinaemic impact. 
There are evidence that the hot oatmeal elicits greater satiety [11] and a lower food intake [12] than Honey Nut Cheerios, a ready-to-eat cereal made from oats. However, it is unknown if ONO will promote greater satiety than a control cereal. In the present study we used cooked cream of rice cereal (CR) as a control because, while CR is similar to ONO in that neither are ready-to-eat cereals and both are consumed in a hydrated form, CR does not contain $\beta$-glucan, the hypothesized major active ingredient in oats. Furthermore, we previously compared the glycaemic impact of cooked oats to cooked CR $[13,14]$ so that, using CR as an anchor, the results for ONO can be compared to the previous results for hot oatmeal.

It has been suggested that comparing the glycaemic responses of individual foods has limited clinical utility because the difference in response will not be maintained when the foods are incorporated into a mixed-meal containing fat, protein and carbohydrate from other foods. Oats may be consumed in a mixed-meal containing milk and additions such as sugar, nuts, and seeds. We hypothesized that $\mathrm{ONO}$, with or without such inclusions, would elicit lower glycaemic and insulinaemic responses than CR, but that the relative difference in glycaemic response between CR and ONO with added sugar, nuts, and seeds would be less than that between the cereals alone.

Therefore, we aimed to compare the glucose, insulin and subjective appetite responses elicited by $\mathrm{ONO}$ with those elicited by CR served alone and with the addition of sugar, nuts and seeds (inclusions) added to both cereals. We determined the effect of these inclusions because they would be present in a commercially available product and may influence the glycemic response.

\section{Materials and methods}

The project was carried out in two research centers as two separate studies each with an open-label, randomized, crossover design using similar methods. CR and ONO fed alone were compared at GI Labs, Inc., Toronto, Ontario (GI Labs), while CR and ONO with inclusions (CRsns and ONOsns, respectively) were compared at the Richardson Center for Functional Foods and Nutraceuticals, University of Manitoba, Winnipeg, Manitoba (RCFFN). The studies were registered at www.clinicaltrials.gov as NCT03150251 and NCT03091946.

\section{Participants}

Participants were males and non-pregnant females aged $18-75$ years with $\mathrm{BMI} \geq 20.0$ and $<35.0 \mathrm{~kg} / \mathrm{m}^{2}$ and fasting serum-glucose $<7.0 \mathrm{mmol} / \mathrm{l}$ (or blood-glucose $<6.3 \mathrm{mmol} / \mathrm{l}$ ). Methods of recruitment and details of inclusion/exclusion criteria are given in supplementary information. The GI Labs protocol was approved by IRB Services, Inc.; the RCFFN protocol and recruiting advertisements were approved by the University of Manitoba Research Ethics Board; all participants provided a written informed consent prior to starting the study.

\section{Study design and procedures}

Eligible participants were studied on separate days over a period of 2-6 weeks. The interval between successive tests was not less than $48 \mathrm{~h}$. On every test day, the participants came to their respective research center in the morning after a $10-12 \mathrm{~h}$ overnight fast (water was allowed). Participants were asked to maintain stable dietary and activity habits throughout the study and to refrain from drinking alcohol, and from unusual levels of food intake or physical activity for $24 \mathrm{~h}$ before each test. If any subject was unwell or had not complied with the experimental conditions, the test was rescheduled for another day.

On each test occasion subjects were weighed, provided two fasting blood samples and rated their hunger. Then, the subjects consumed a test-meal which they were asked to consume within $10 \mathrm{~min}$. At the first bite a timer was started and 10 additional blood samples were taken at intervals over the next $3 \mathrm{~h}$. Subjective hunger was assessed at intervals of over $3 \mathrm{~h}$ in Toronto or $4 \mathrm{~h}$ in Winnipeg. During the $3-4 \mathrm{~h}$ of the test, participants remained seated quietly. After the last hunger rating had been completed, participants were offered a snack and allowed to leave. Details of procedures are given in supplementary information.

\section{Test-meals}

At GI Labs the ONO test-meal consisted of $40 \mathrm{~g}$ oats (Quaker Kettle Hearty Overnight Oats, Chicago, IL) stirred into $110 \mathrm{~g}$ skim milk, soaked overnight $(15-17 \mathrm{~h})$ at $4{ }^{\circ} \mathrm{C}$, and consumed cold with $160 \mathrm{ml}$ water; the $\mathrm{CR}$ test-meal consisted of $28.8 \mathrm{~g}$ cream of rice cereal (B\&G Foods, Inc., Parsippany, NJ, USA) stirred into $160 \mathrm{~g}$ water, microwaved on high for $3 \mathrm{~min}$, stirred, left to sit for $1 \mathrm{~min}$ and served with $110 \mathrm{~g}$ skim milk. At GI Labs all subjects also tested CR, which had been soaked overnight in milk, but these results are not presented here as this does not represent how consumers eat the product.

At RCFFN the ONOsns test-meal consisted of a sachet containing $40.5 \mathrm{~g}$ oats plus $28.5 \mathrm{~g}$ of inclusions $(9.3 \mathrm{~g}$ sucrose, $8.1 \mathrm{~g}$ sliced almonds, $4.6 \mathrm{~g}$ toasted coconut, $3.5 \mathrm{~g}$ white quinoa flakes, $2.3 \mathrm{~g}$ whole flaxseed, $0.4 \mathrm{~g}$ sodium chloride and $0.3 \mathrm{~g}$ natural flavors) stirred into $110 \mathrm{~g}$ skim milk soaked overnight $(15-17 \mathrm{~h})$ in a refrigerator, and consumed cold with $160 \mathrm{ml}$ water; the CRsns test-meal consisted of a sachet containing $28.8 \mathrm{~g}$ cream of rice cereal 
Table 1 Composition of test meals

\begin{tabular}{|c|c|c|c|c|c|c|c|c|}
\hline & \multirow[t]{2}{*}{ Abbrev. } & \multirow[t]{2}{*}{ Weight (g) } & \multirow{2}{*}{$\begin{array}{l}\text { Energy (kJ } \\
(\mathrm{kcal}))\end{array}$} & \multirow{2}{*}{ Protein $(\mathrm{g})$} & \multirow{2}{*}{$\begin{array}{l}\text { Fat } \\
(\mathrm{g})\end{array}$} & \multicolumn{3}{|c|}{ Carbohydrate (g) } \\
\hline & & & & & & Total & Fiber & Avail. \\
\hline Overnight oats & ONO & 40 & $628(150)$ & 5 & 4 & 27 & 4 & 23 \\
\hline Cream of rice & $\mathrm{CR}$ & 28.8 & 427 (102) & 1.9 & 0 & 23 & 0 & 23 \\
\hline $\begin{array}{l}\text { Overnight oats plus sugar, } \\
\text { nuts, and seeds }\end{array}$ & ONOsns & 69 & $1210(289)$ & 8.3 & 10.4 & 43.8 & 6.3 & 37.5 \\
\hline $\begin{array}{l}\text { Cream of rice plus sugar, } \\
\text { nuts, and seeds }\end{array}$ & CRsns & 57.3 & $1005(240)$ & 4.8 & 7.5 & 39.4 & 2.5 & 36.9 \\
\hline Skim milk ${ }^{\mathrm{a}}$ & - & 110 & $155(37)$ & 3.7 & 0 & 5.5 & 0 & 5.5 \\
\hline
\end{tabular}

Avail., available carbohydrate (total carbohydrate minus dietary fiber, rounded to nearest $0.1 \mathrm{~g}$ ). Nutrition information for cereals provided by PepsiCo

${ }^{a}$ Nutrition information for milk based on the Nutrition Facts Table assuming the density of skim milk to be $1.036 \mathrm{~g} / \mathrm{ml}$; thus $110 \mathrm{~g}$ milk $=106 \mathrm{ml}$. plus $28.5 \mathrm{~g}$ of inclusions (same as added to ONOsns) stirred into $160 \mathrm{~g}$ water, microwaved on high for $3 \mathrm{~min}$, stirred, left to sit for $1 \mathrm{~min}$ and served with $110 \mathrm{~g}$ skim milk.

The composition of the test-meals is shown in Table 1. At both centers test-meals were matched for avCHO and served with a drink of one or two cups of coffee or tea or water with $30 \mathrm{ml}$ milk (2\% at GI labs and skim at RCFFN) and non-caloric sweetener if desired; the type and volume of drink selected on the first visit was consumed on the subsequent visit. A description of the randomization procedures is given in supplementary information [15].

\section{Biochemical analysis}

At GI Labs, finger-prick whole blood-glucose was measured using a YSI model 2300 STAT analyzer (Yellow Springs, OH, USA) and serum-insulin was measured using the Human Insulin EIA Kit (Alpco Diagnostics, Salem, NH, USA, catalog \# 80-INSHU-E10.1). At RCFFN, finger-prick glucose was measured using a glucometer (StatStrip Glucose, Nova Biomedical Waltham, MA, USA) calibrated to provide values of plasma glucose [16] and serum human insulin was measured by immunoassay (Meso Scale Discovery, Rockville, MD, USA). Details of biochemical methods are given in supplementary information.

\section{Calculations}

Incremental areas under the blood-glucose and seruminsulin response curves (iAUC), ignoring area below fasting, were calculated using the trapezoid rule [17, 18]. Fasting glucose and insulin were taken to be the mean of the concentrations in the two fasting samples. For subjective hunger scores, net incremental area under the curve (netAUC), and subtracting area below the baseline, was calculated using the trapezoid rule $[11,12]$.

\section{Statistical analysis}

The data from each study were analyzed separately. At both centers the primary endpoint was glucose iAUC from 0 to 2 $\mathrm{h}$ (iAUC0-2). Secondary endpoints are given in supplementary information. Paired $t$-tests were used to determine whether differences were statistically significant, with the criterion for significance being a two-tailed $P<0.05$. Response curves were analysed using repeated-measures analysis of variance (RMANOVA) examining for the main effects of time and test-meal, and the time $\times$ test-meal interaction. After demonstration of significant heterogeneity, RMANOVA was used to determine the effects of test-meal at the specific time points. With $n=40$ subjects, each study had $80 \%$ power to detect a difference of $16 \%$, and $90 \%$ power to detect a difference of $19 \%$ in the primary endpoint of glucose iAUC0-2.

The results of the two studies were compared with each other using Fisher's exact tests for categorical variables or unpaired $t$-test for continuous variables.

\section{Results}

GI Labs recruited 40 eligible subjects, all of whom completed the study; RCFFN recruited 43 eligible subjects, 3 of whom did not complete the study leaving 40 who completed the study (Fig. 1). The characteristics of the participants who completed the studies are shown in Table 2.

\section{Blood-glucose responses}

Glucose response curves are shown in Fig. 2. Mean glucose iAUC from 0 to $2 \mathrm{~h}$ (iAUC0-2), after ONO and ONOsns were $33 \%(P<0.0001)$ and $24 \%(P=0.0003)$, less than after CR and CRsns, respectively (Table 3). Mean glucose iAUC0-2 after CRsns and ONOsns were significantly 


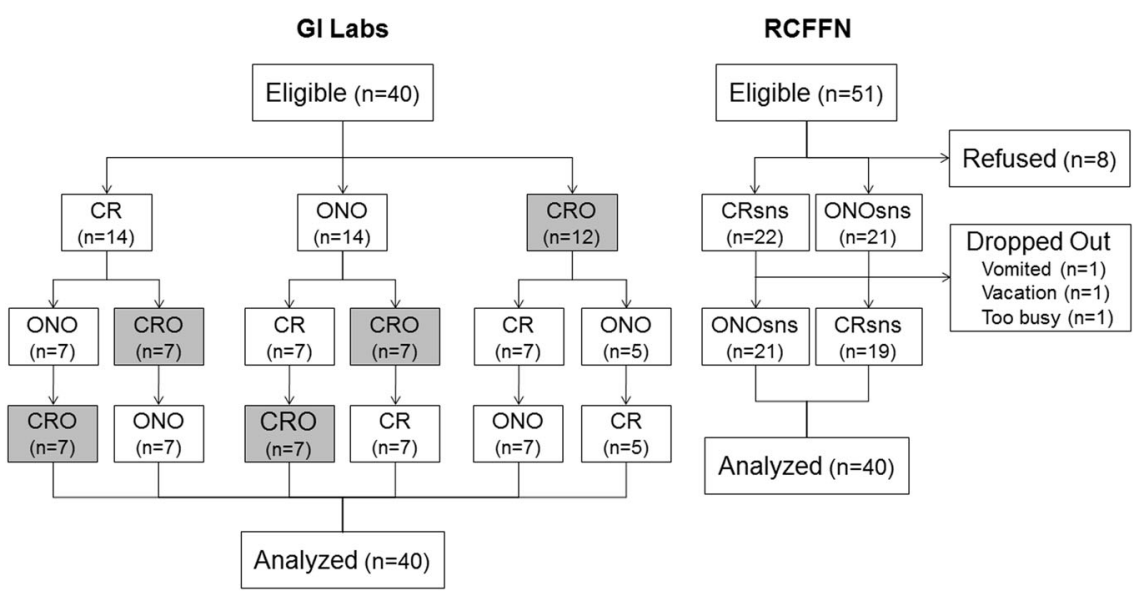

Fig. 1 Flowchart. Footnote: GI Labs, Glycemic Index Laboratories, Inc., Toronto, Ontario tested Cream of Rice cereal (CR), oats soaked overnight in skim-milk (ONO) and cream of rice soaked overnight in skim-milk (CRO; results not presented here). RCFFN, Richardson

Table 2 Subject characterisics

\begin{tabular}{|c|c|c|c|}
\hline & GI Labs & RCFFN & $P$ \\
\hline Sex (M:F) & $24: 16$ & $20: 20$ & ns \\
\hline Age (years) & $39.2 \pm 13.1$ & $36.7 \pm 16.2$ & ns \\
\hline Weight (kg) & $75.3 \pm 11.9$ & $72.8 \pm 12.5$ & ns \\
\hline Body mass index $\left(\mathrm{kg} / \mathrm{m}^{2}\right)$ & $26.5 \pm 3.1$ & $24.8 \pm 3.3$ & 0.016 \\
\hline Fasting plasma glucose $(\mathrm{mmol} / \mathrm{l})$ & $4.6 \pm 0.4$ & $5.2 \pm 0.6$ & $<0.0001$ \\
\hline $\begin{array}{l}\text { Blood } \\
\text { pressure }\end{array}$ & $\begin{array}{l}120.1 \pm \\
112.3\end{array}$ & $\begin{array}{l}111.7 \pm \\
14.0\end{array}$ & 0.006 \\
\hline $\begin{array}{l}\text { Diastolic } \\
(\mathrm{mmHg})\end{array}$ & $74.6 \pm 9.9$ & $72.0 \pm 9.7$ & ns \\
\hline
\end{tabular}

Values are means $\pm \mathrm{SD}$

greater than the respective values after CR and ONO $(P<$ 0.001 and $P<0.001)$. Similar effects within and between centers were seen for iAUC0-3 $(P<0.001$ and $P<0.001)$ and peak rise $(P<0.001$ and $P<0.001)$ (Table 3$)$.

Blood-glucose was significantly above baseline at $2 \mathrm{~h}$ after ONOsns $(P=0.013)$, similar to baseline at $2 \mathrm{~h}$ after ONO and CRsns, and below baseline at $2 \mathrm{~h}$ after $\mathrm{CR}(P=0.003$; Table $3)$. Significantly more subjects had $2 \mathrm{~h}$ glucose above baseline after ONO $(55 \%)$ than $\mathrm{CR}(32.5 \%)(P=0.024)$, but the difference between ONOsns (65\%) and CRsns (55\%) was not significant (Table 2; Fig. 3). More subjects had glucose above baseline at $2 \mathrm{~h}$ after CRsns compared to CR (55\% vs. $32.5 \%$, $P=0.023)$, but the difference between ONOsns $(65 \%)$ and ONO $(55 \%)$ was not significant.

\section{Serum-insulin responses}

Insulin response curves are shown in Fig. 2. Mean insulin iAUC from 0 to $2 \mathrm{~h}$ (iAUC0-2), iAUC from 0 to $3 \mathrm{~h}$ (iAUC0-3) and peak rise after $\mathrm{ONO}$ and ONOsns were
Center for Functional Foods and Nutraceuticals, University of Manitoba, Winnipeg, Manitoba tested CR with added sugar, nuts and seeds (CRsns) and ONO with added sugar, nuts and seeds (ONOsns)

significantly higher than their respective values after CR and CRsns (Table 3). Mean insulin responses after CRsns and ONOsns were greater than the respective values after CR and ONO for iAUCO-2, iAUC2-3 and iAUCO-3 (Table 3).

\section{Subjective hunger}

Subjective hunger ratings after CR and CRsns were similar to those after ONO and ONOsns (Supplementary Figure 1). Subjective ratings for desire to eat, fullness, and prospective consumption after ONO were similar to those after CR (not shown). Mean hunger rating was significantly below baseline at $2 \mathrm{~h}$ after both $\mathrm{CR}$ (mean difference $(95 \%$ confidenceinterval)), $10.3(18.2-2.3) \mathrm{mm}(P=0.013)$ and ONO, 9.7 (18.1-1.4) $\mathrm{mm}(P=0.023)$ but did not differ significantly from baseline at $2 \mathrm{~h}$ after CRsns and ONOsns.

\section{Discussion}

ONO elicited a significantly lower glycaemic response than $\mathrm{CR}$, regardless of whether the cereals were tested alone or with the addition of sugar, nuts and seeds. The glycaemic profiles after ONO and ONOsns were flatter than those after $\mathrm{CR}$ and CRsns with a lower peak rise, higher glucose at 120 or $180 \mathrm{~min}$, and a larger percentage of subjects with glucose above baseline at $2 \mathrm{~h}$.

The subjects at RCFFN who consumed the test-meals with added sugar, nuts, and seeds tended to be younger and had significantly lower BMI and systolic blood pressure than those at GI Labs; despite this, RCFFN subjects had significantly higher fasting glucose and significantly higher postprandial glucose and insulin responses. The higher 


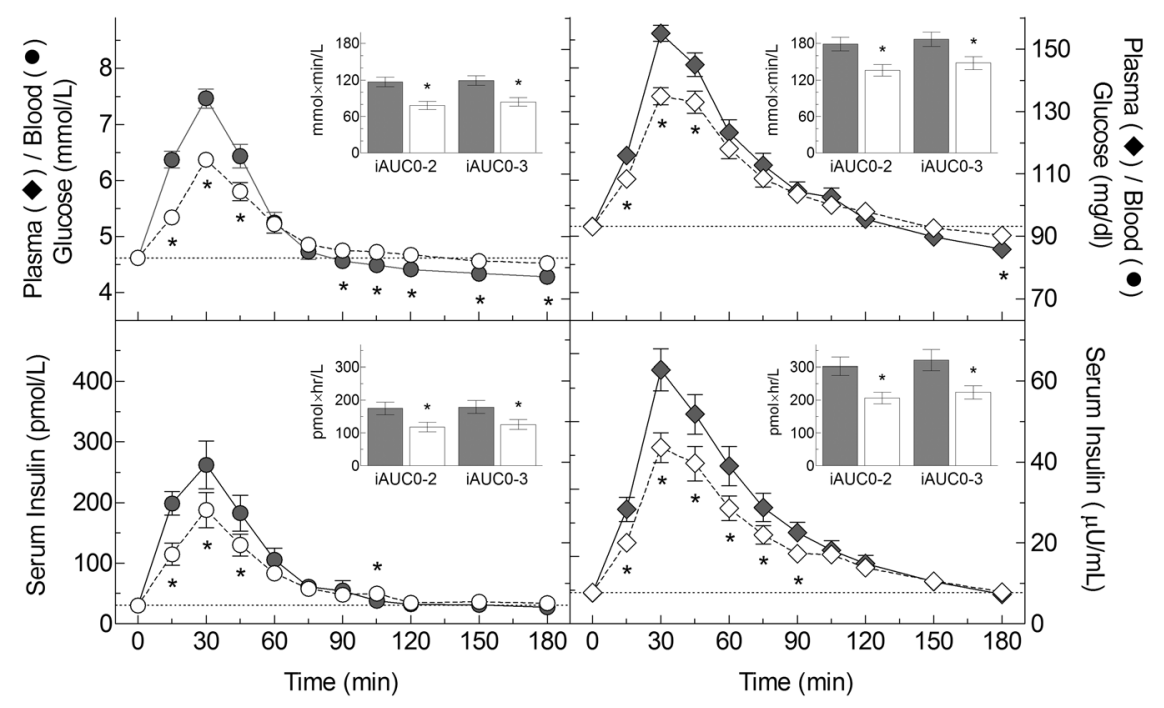

Fig. 2 Glucose and insulin responses. Main graphs: blood or plasma glucose (top) and serum-insulin (bottom) concentrations elicited by cooked Cream of Rice cereal (filled symbols) and oatmeal soaked overnight in skim-milk (open symbols). Cereals were fed alone (circles) or contained added sugar, nuts, and seeds (diamonds). Points are

fasting glucose in RCFFN subjects (Fig. 1) is explained by the fact that at RCFFN glucose was measured using a glucometer calibrated to give plasma glucose [19], which yields values approximately $0.7 \mathrm{mmol} / \mathrm{l}$ higher than whole blood-glucose, as measured by GI Labs [19]. The $\sim 60 \%$ higher glucose iAUC in RCFFN subjects is partly explained by the higher avCHO content of the test-meals they consumed and partly because using a glucometer calibrated to give plasma glucose yields a significantly higher iAUC than measuring whole blood-glucose [19]. Nevertheless, the method of measuring glucose would not be expected to have a significant effect on the glycaemic response after ONO relative to CR [19].

The clinical relevance of studies comparing the glycaemic responses of individual foods has been questioned because responses will differ when the foods are consumed as part of mixed meals containing other sources of carbohydrate, fat and/or protein [20-23]. However, we believe it is clinically appropriate to compare glycaemic responses of individual foods because the effect on the glycaemic response of adding other sources of carbohydrate, fat and/or protein to the individual food can be estimated from data on the dose-response effects of various types of carbohydrate, fat and protein on glycaemic responses [17, 24-27]. For example, here we determined the glycaemic responses elicited by ONO and CR both with and without inclusions. Relative to CR, the mean glycaemic response after ONO (no inclusions), 67\%, tended to be less than that for ONOsns (with inclusions), 76\%. However, this difference is almost exactly that expected based on the composition of the inclusions. In Supplementary Information, we show means \pm SEM for $n=40$ subjects. Insets: Incremental areas under the curves of glucose and insulin from 0 to $2 \mathrm{~h}$ (iAUC0-2) and $0-3 \mathrm{~h}$ (iAUC0-3). Values are means \pm SEM for $n=40$ subjects. * Significant difference between cream of rice and overnight oats

how the carbohydrate, protein and fat content of the inclusions predict that ONOsns would elicit a glycaemic response $77 \%$ of CRsns. It is not feasible to test every one of the virtually infinite number of possible meals containing ONO; our results suggest this is not necessary since the relative glycaemic impact of mixed meals can be determined from their component parts.

Mean insulin iAUC0-2 h, iAUC0-3 and peak rise were significantly lower after ONO than CR and significantly lower after ONOsns than CRsns. The \% reductions in insulin were similar to or greater than those for glucose. This is important because it has been suggested that reductions in glycaemic response are only beneficial if they are accompanied by reductions in insulin response of a similar (or greater) magnitude [28, 29]. Reduced postprandial glucose responses can be due either to a reduced rate of entry of glucose into the circulation [30] or to reduced hepatic glucose production [31] or to an increased rate of glucose disposal because of an increased insulin response. Since we found no evidence of disproportionately high insulin responses, the present results support the hypothesis that ONO and ONOsns reduced glycaemic responses because they contain slowly absorbed carbohydrates.

A marker of slow carbohydrate absorption could be glucose above fasting at $2 \mathrm{~h}$ after eating, and we found that the percentage of subjects with glucose above baseline at 2 $\mathrm{h}$ was significantly higher after ONO than CR. However, whether an individual's blood-glucose is above fasting at 2 $\mathrm{h}$ depends not only on whether dietary carbohydrates are slowly absorbed, but also on how much carbohydrate is 
Table 3 Primary and major secondary endpoints for glucose and insulin

\begin{tabular}{|c|c|c|c|c|}
\hline & \multicolumn{2}{|c|}{ GI Labs $(n=40)$} & \multicolumn{2}{|c|}{ RCFFN $(n=40)$} \\
\hline & $\mathrm{CR}$ & ONO & CRsns & ONOsns \\
\hline \multicolumn{5}{|l|}{ Glucose } \\
\hline iAUC0-2 $(\mathrm{mmol} \times \mathrm{min} / \mathrm{l})$ & $117.2 \pm 49.5$ & $78.3 \pm 41.8^{*}$ & $178.9 \pm 71.4^{\dagger}$ & $135.9 \pm 60.4^{\dagger *}$ \\
\hline iAUC2-3 $(\mathrm{mmol} \times \mathrm{min} / \mathrm{l})$ & $1.7 \pm 3.6$ & $5.4 \pm 7.4 *$ & $7.6 \pm 9.7 *$ & $12.1 \pm 15.3^{*}$ \\
\hline iAUC0-3 $(\mathrm{mmol} \times \mathrm{min} / \mathrm{l})$ & $118.9 \pm 49.6$ & $83.7 \pm 44.4^{*}$ & $186.5 \pm 75.2^{\dagger}$ & $148.0 \pm 67.2^{\dagger *}$ \\
\hline Peak rise $(\mathrm{mmol} / \mathrm{l})$ & $2.97 \pm 0.80$ & $1.87 \pm 0.60^{*}$ & $3.72 \pm 0.89^{\dagger}$ & $2.72 \pm 0.87^{\dagger *}$ \\
\hline Fasting $(\mathrm{mmol} / \mathrm{l})$ & $4.62 \pm 0.40$ & $4.62 \pm 0.42$ & $5.18 \pm 0.51$ & $5.17 \pm 0.48$ \\
\hline $2 \mathrm{~h}(\mathrm{mmol} / \mathrm{l})$ & $4.41 \pm 0.45^{\ddagger}$ & $4.67 \pm 0.40^{*}$ & $5.31 \pm 0.80$ & $5.44 \pm 0.54^{\ddagger}$ \\
\hline $2 \mathrm{~h}$ increment $(\mathrm{mmol} / \mathrm{l})$ & $-0.21 \pm 0.42$ & $0.05 \pm 0.36^{*}$ & $0.13 \pm 0.68^{\dagger}$ & $0.27 \pm 0.65^{\ddagger}$ \\
\hline Above:below fasting at $2 \mathrm{~h}$ & $13: 27$ & $22: 18^{\mathrm{a}}$ & $22: 18^{b}$ & $26: 14$ \\
\hline \multicolumn{5}{|l|}{ Insulin } \\
\hline iAUC0-2 $(\mathrm{pmol} \times \mathrm{h} / \mathrm{l})$ & $174.6 \pm 120.7$ & $117.6 \pm 90.1 *$ & $302.3 \pm 175.3^{\dagger}$ & $205.7 \pm 113.9^{\dagger *}$ \\
\hline iAUC2-3 $(\mathrm{pmol} \times \mathrm{h} / \mathrm{l})$ & $4.2 \pm 7.3$ & $8.1 \pm 11.8$ & $22.7 \pm 32.8^{*}$ & $19.2 \pm 21.6^{*}$ \\
\hline iAUC0-3 $(\mathrm{pmol} \times \mathrm{h} / \mathrm{l})$ & $178.7 \pm 123.0$ & $125.7 \pm 92.4^{*}$ & $325.0 \pm 196.9^{\dagger}$ & $225.9 \pm 129.8^{\dagger *}$ \\
\hline Peak rise (pmol/l) & $278 \pm 197$ & $185 \pm 146^{*}$ & $367 \pm 180^{\dagger *}$ & $250 \pm 139^{\dagger}$ \\
\hline
\end{tabular}

Results are given as means \pm SD for $n=40$ subjects

$i A U C$ incremental area under the curve

*Differs significantly from respective CR or CRsns by paired $t$-test $(p<0.05)$

${ }^{\dagger}$ Differs significantly from corresponding mean from GI Labs by unpaired $t$-test $(p<0.05)$

${ }^{\ddagger}$ Differs significantly from fasting glucose by paired $t$-test $(p<0.05)$

${ }^{a}$ Percentage above fasting after ONO differs from CR by Fisher's exact test $(p<0.05)$

${ }^{b}$ Percentage above fasting after CRsns differs from CR by Fisher's exact test $(p<0.05)$ consumed, the individual's carbohydrate tolerance (carbohydrate intolerance is defined by high blood-glucose $2 \mathrm{~h}$ after eating), and perhaps other factors. The fact that RCFFN subjects consumed a larger test-meal may explain why, overall, more subjects at RCFFN had glucose above baseline at $2 \mathrm{~h}$ than at GI Labs.

Subjects at RCFFN had lower subjective hunger ratings than those at GI Labs, which could have been due to a shorter fast or an earlier start time, or to differences in subject perceptions. The subjective nature of hunger ratings is also shown by the counter-intuitive finding that subjects at GI Labs reported being less hungry than baseline $2 \mathrm{~h}$ after consuming 580-780 kJ (140-90 kcal) test-meals, whereas subjects at RCFFN reported being as hungry as at baseline $2 \mathrm{~h}$ after consuming $1160-1370 \mathrm{~kJ}(280-330 \mathrm{kcal})$ testmeals. We were unable to demonstrate any significant difference in subjective hunger ratings after ONO compared to CR or ONOsns compared to CRsns.

We did not compare the glycaemic response elicited by ONO with that of cooked oatmeal. However, we previously compared the glycaemic impact of various types and amounts of cooked oats to those of avCHO-matched portions of cooked CR [13, 14]. Thus, by using CR as an anchor, the results for ONO in this study can be compared with those of hot oatmeal in the previous studies. Here, ONO elicited an iAUC0 $-2 \mathrm{~h}$ (mean \pm SEM) $69.1 \pm 4.6 \%$ of that elicited by $\mathrm{CR}$, a value significantly less than that for $40 \mathrm{~g}$ Quick Oatmeal (Quaker, Cedar Rapids, IA), 89.9 \pm $7.2 \%(P=0.018)$ and significantly less than the mean for the 30,40 , and $60 \mathrm{~g}$ servings of oatmeal, $81.9 \pm 3.3 \%(P=$ $0.029)$ despite the fact that the Quick Oatmeal contained $40 \%$ more dietary fiber per $40 \mathrm{~g}$ serving than ONO. The relative response for $\mathrm{ONO}, 69.1 \pm 4.6 \%$, was also significantly less than those for Quaker Instant Oatmeal (104.4 $\pm 5.1 \%, P<0.05)$ and Quaker old fashioned oats $(92.4 \pm$ $6.7 \%, P<0.05)$ and similar to that for Quaker steel cut oatmeal $(72.4 \pm 6.3)$, each tested in $n=30$ subjects [14]. Taken together, these results suggest that soaking oats overnight in milk may reduce their glycaemic impact relative to hot oatmeal, however, this must be confirmed by a direct comparison of cooking vs. soaking.

The strengths of the study include the relatively large number of subjects tested in each of two different centers using the same blood sampling schedule and the same testmeals, except for the addition of sugar, nuts, and seeds at RCFFN, inclusions that would likely be found in commercial ONO products. The fact that the centers used different analytical methods for glucose and insulin and that the two population studied differed in several respects serve to enhance the robustness and applicability of the findings.

It is concluded that oats soaked overnight in skim-milk elicit significantly lower glycaemic and insulinaemic 

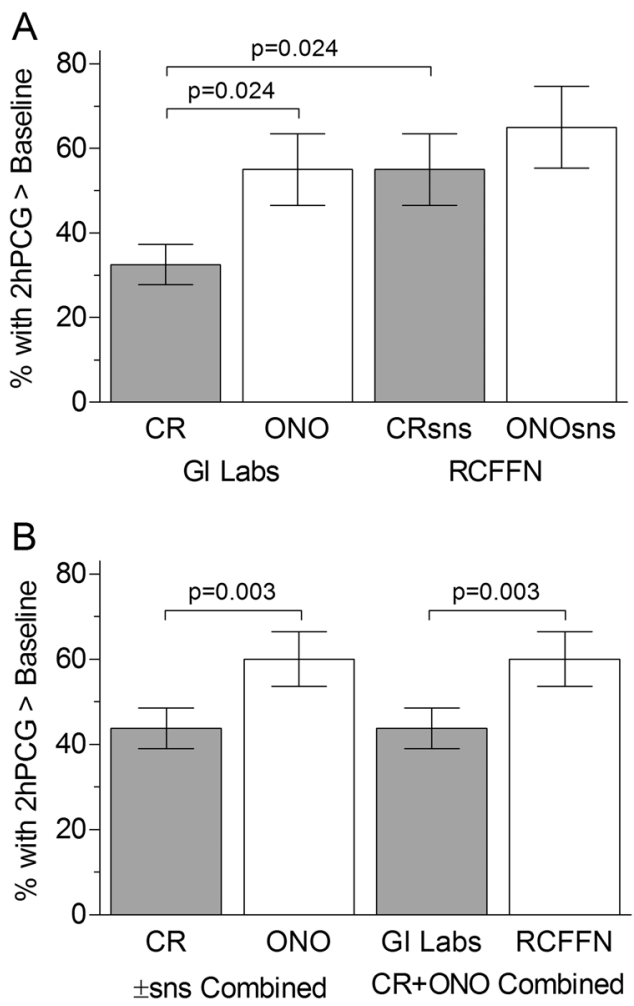

Fig. 3 Glucose above baseline at $2 \mathrm{~h}$. Percentage of subjects with glucose $2 \mathrm{~h}$ after eating (2hPCG) greater than baseline (fasting glucose). Bars are percentages $\pm 95 \%$ confidence intervals. a Data for individual test-meals (each bar represents the percentage of $n=$ 40 subjects). b Each bar represents the percentage of $n=80$ subjects; $\mathrm{CR}, \mathrm{CR}$ and CRsns combined; ONO, ONO and ONOsns combined; GI Labs, CR and ONO combined; RCFFN, CRsns and ONOsns combined

responses than cooked Cream of Rice cereal whether the cereals are consumed alone or with inclusions. The findings that significantly more participants had glucose above fasting $2 \mathrm{~h}$ after consuming ONO than $2 \mathrm{~h}$ after CR, with or without inclusions, support the hypothesis that overnight oats contain slowly absorbed carbohydrate.

Acknowledgements PepsiCo, Inc. provided funding for the work, assisted in the design of the protocol and provided the test cereals. PepsiCo reviewed and provided comments on the manuscript draft, but TMSW determined its final content. The views expressed in this article are those of the authors and do not necessarily reflect the opinion or policies of PepsiCo, Inc.

\section{Compliance with ethical standards}

Conflict of interest TMSW, TMSW's wife and ALJ are part owners and employees of GI Labs, Inc., a contract research organization. Neither they nor GI Labs will own any of the intellectual property which may arise from this research, nor do they have any financial interest in PepsiCo, Inc. or any of its subsidiaries. JJ, and YC are employees of PepsiCo, Inc., which manufactures oatmeal products under the brand name Quaker Oats ${ }^{\circledR}$. The remaining authors declare that they have no conflict of interest.

Open Access This article is licensed under a Creative Commons Attribution 4.0 International License, which permits use, sharing, adaptation, distribution and reproduction in any medium or format, as long as you give appropriate credit to the original author(s) and the source, provide a link to the Creative Commons license, and indicate if changes were made. The images or other third party material in this article are included in the article's Creative Commons license, unless indicated otherwise in a credit line to the material. If material is not included in the article's Creative Commons license and your intended use is not permitted by statutory regulation or exceeds the permitted use, you will need to obtain permission directly from the copyright holder. To view a copy of this license, visit http://creativecommons. org/licenses/by/4.0/.

\section{References}

1. Tosh SM, Chu YF. Systematic review of the effect of processing of whole-grain oat cereals on glycaemic responses. Brit J Nutr. 2015;114:1256-62.

2. Jenkins DJA, Wolever TMS, Taylor RH, Barker HM, Fielden H, Baldwin JM, et al. Glycemic index of foods: a physiological basis for carbohydrate exchange. Am J Clin Nutr. 1981;34:362-6.

3. Jenkins DJA, Wolever TMS, Jenkins AL, Thorne MJ, Lee R, Kalmusky J, et al. The glycaemic index of foods tested in diabetic patients: a new basis for carbohydrate exchange favouring the use of legumes. Diabetologia. 1983;24:257-64.

4. Wolever TMS, Katzman-Relle L, Jenkins AL, Vuksan V, Josse RG, Jenkins DJA. Glycaemic index of 102 complex carbohydrate foods in patients with diabetes. Nutr Res. 1994;14:651-69.

5. Wood PJ. Oat $\beta$-glucan: structure, location and properties. In: Webstger FH (ed.), Oats: chemistry and technology. (AACC Inc., St Paul, MN) 1986; 121-52.

6. Wood PJ, Braaten JT, Scott FW, Riedel KD, Wolynetz MS, Collins MW. Effect of dose and modification of viscous properties of oat gum on plasma glucose and insulin following an oral glucose load. Bri J Nutr. 1994;72:731-43.

7. Wood PJ, Beer MU, Butler G. Evaluation of role of concentration and molecular weight of oat $\beta$-glucan in determining effect of viscosity on plasma glucose and insulin following an oral glucose load. Bri J Nutr. 2000;84:19-23.

8. Jenkins DJA, Wolever TMS, Leeds AR, Gassull MA, Haisman P, Dilawari J, et al. Dietary fibres, fibre analogues, and glucose tolerance: importance of viscosity. BMJ. 1978;1:1392-4.

9. Raben A, Tagliabue A, Christensen NJ, Madsen J, Holst JJ, Astrup A. Resistant starch: the effect on postprandial glycemia, hormonal response, and satiety. Am J Clin Nutr. 1994;60:544-51.

10. Lan-Pidhainy X, Brummer Y, Tosh SM, Wolever TM, Wood PJ. Reducing beta-glucan solubility in oat bran muffins by freezethaw treatment attenuates its hypoglycemic effect. Cereal Chem. 2007;84:512-7.

11. Rebello CJ, Johnson WD, Martin CK, Xie W, O'Shea M, Kurilich A, et al. Acute effect of oatmeal on subjective measures of appetite and satiety compared to a ready-to-eat cereal: a randomized crossover trial. J Am Col Nutr. 2013;32:272-9.

12. Rebello CJ, Johnson WD, Martin CK, Han H, Chu YF, Bordenave $\mathrm{N}$, et al. Instant oatmeal increases satiety and reduces energy intake compared to a ready-to-eat oat-based breakfast cereal: a randomized cross-over trial. J Am Col Nutr. 2016;35:41-49.

13. Wolever TMS, van Klinken BJ-W, Spruill SE, Jenkins AL, Chu Y, Harkness L. Effect of serving size and addition of sugar on the 
glycemic response elicited by oatmeal: a randomized, cross-over study. Clin Nutr Espen. 2016;16:48-54.

14. Wolever TMS, Johnson J, Jenkins AL, Campbell JC, Ezatagha A, Chu Y. Impact of oat processing onglycaemic and insulinaemic responses in healthy humans: a randomized clinical trial. Submitted for publication.

15. Anderson GH, Catherine NLA, Woodend DM, Wolever TMS. Inverse association between the effect of carbohydrates on bloodglucose and subsequent short-term food intake in young men. Am J Clin Nutr. 2002;76:1023-30.

16. Chan PCR, Rozmanc M, Seiden-Long I, Kwan J. Evaluation of a point-of-care glucose meter to general use in complex tertiary care facilities. Clin Biochem. 2009;42:1104-12.

17. Wolever TMS, Jenkins DJA. The use of the glycemic index in predicting the blood glucose response to mixed meals. Am J Clin Nutr. 1986;43:167-72.

18. Wolever TMS. Effect of blood sampling schedule and method calculating the area under the curve on validity and precision of glycaemic index values. Brit J Nutr. 2004;91:295-300.

19. Velangi A, Fernandes G, Wolever TMS. Evaluation of a glucose meter for determining the glycemic responses of foods. Clin Chim Acta. 2005;356:191-8.

20. Hätönen KA, Virtamo J, Eriksson JG, Sinkko HK, Sundvall JE, Valsta LM. Protein and fat modify the glycaemic and insulinaemic responses to a mashed potato-based meal. Brit $\mathrm{J}$ Nutr. 2011;106:248-53.

21. Dodd H, Williams S, Brown R, Venn B. Calculating meal glycemic index by using measured and published food values compared with directly measured meal glycemic index. Am J Clin Nutr. 2011;94:992-6.

22. Jones JM. Glycemic index: the state of the science, part 1: the measure and its variability. Nutr Today. 2012;47:207-13.

23. Meng H, Matthan NR, Ausman LM, Lichtenstein AH. Effect of macronutrients and fiber on postprandial glycemic responses and meal glycemic index and glycemic load value determinations. Am J Clin Nutr. 2017;105:842-53.
24. Wolever TMS, Bolognesi C. Source and amount of carbohydrate affect postprandial glucose and insulin in normal subjects. J Nutr. 1996;126:2798-806.

25. Lan-Pidhainy X, Wolever TMS. The hypoglycemic effect of fat and protein is not attenuated by insulin resistance. Am J Clin Nutr. 2010;91:98-105.

26. Gunnerud UJ, Ostman EM, Bjorck IM. Effects of whey proteins on glycaemia and insulinaemia to an oral glucose load in healthy adults; a dose-response study. Eur J Clin Nutr. 2013;67:749-53.

27. Owen B, Wolever TMS. Effect of fat on glycaemic responses in normal subjects: a dose-response study. Nutr Res. 2003; 23:1341-7.

28. EFSA Panel on dietetic Products, Nutrition and Allergies (NDA), Scientific Opinion on the substantiation of health claims related to beta-glcuans from oats and barley and maintenance of normal blood LDL-cholesterol concentrations (ID1236, 1299), increase in satiety leading to a reduction in energy inake (ID 851,852 ), reduction in post-prandial glycaemic response (ID 821,824 ), and "digestive function" (ID 850) pursuant to Article 13(1) of Regulation (EC) No 1924/2006. EFSA J. 2011; 9: 2207.

29. Bureau of Nutritional Sciences, Food Directorate, Health Products and Food Branch, Health Canada, Draft guidance document on food health claims related to the reduction in post-prandial glycaemic response, June, 2013. https://chfa.ca/images/uploads/2012/ 08/Post-Prandial-Glycaemic-Response-Draft-Guidance.pdf. Accessed 17 May 2017.

30. Nazare J-A, Normand S, Triantafyllou AO, de la Perrière AB, Desage M, Laville M. Modulation of the postprandial phase by beta-glucan in overweight subjects: effects on glucose and insulin kinetics. Mol Nutr Food Res. 2009;53:361-9.

31. Boers HM, van Dijk TH, Hiemstra H, Hoogenraad AR, Mela DJ, Peters HPF, et al. Effect of fibre additions to flatbread flour mixes on glucose kinetics: a randomised controlled trial. Brit $\mathbf{J}$ Nutr. 2017;118:777-87. 